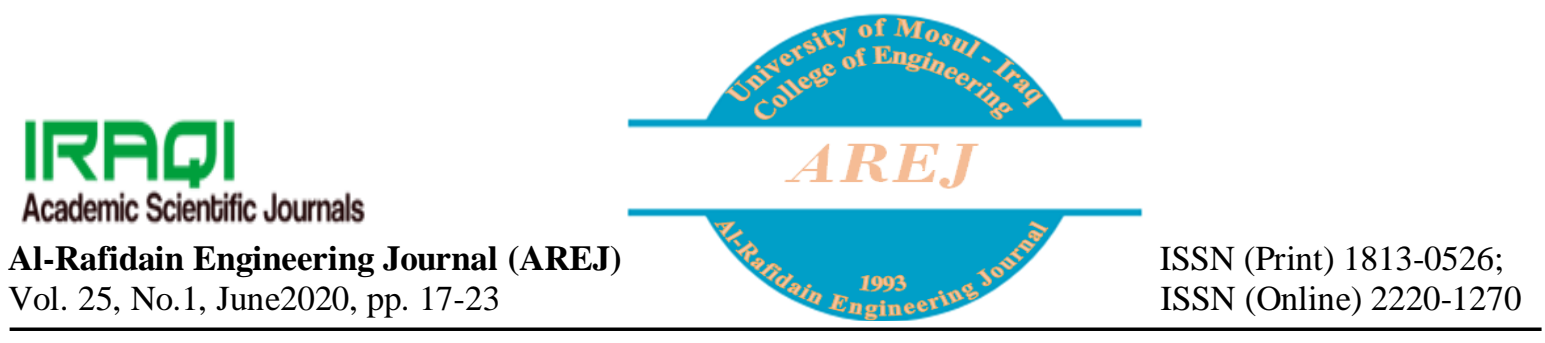

\title{
Strengthening and Rehabilitation of Concrete Prisms Using GFRP Sheets
}

\author{
Ashtar S. Al-Luhybi \\ aziztaher@uomosul.edu.iq
}

\author{
Bayar J. Al- Sulayfani \\ dr.bayar.alsulayvani@uomosul.edu.iq
}

Civil Engineering Department, Collage of Engineering, University of Mosul

Received: 10/1/2020

Accepted: 16/5/2020

\begin{abstract}
The use of external strengthening by fiber reinforced polymer (FRP) technology has significantly increased in recent decades. This is because (FRP) has the properties that make it the most suitable option for strengthening and rehabilitation of damaged concrete structures instead of using traditional materials such as steel plates. In this paper, the behaviour of non-reinforced concrete beams externally wrapped with Glass Fiber Reinforced Polymer (GFRP) sheets has been examined. Fourteen unreinforced concrete prisms were cast with a rectangular section of $(150 \times 125 \mathrm{~mm})$ and a length of $(760 \mathrm{~mm})$, these specimens were divided into five group. First group was not externally wrapped with GFRP sheets (control specimens), and the remaining groups were GFRP wrapped with a variable number of GFRP layers (thickness of wrapping). In the first stage of study, the prisms have been tested and the effect of external wrapping and increasing the wrapping thickness on the behaviour of prisms was observed. In the second stage, the unwrapped concrete prisms that were tested and failed (control specimens) were rehabilitated by externally wrapping them with one layer of GFRP sheets. The results have shown that wrapping with GFRP sheets increased the capacity of the prisms and failure load had reached to (342.5\%) for prisms wrapped with three layers when compared to the control specimens. It was also noticed that there was an increase in the toughness of the prisms by increasing the number of GFRP layers. The results have shown that there was a decrease in the failure load of the four layer wrapped prisms, and this was due to the early failure of the prisms due to the debonding of the GFRP sheets from the prism surface. The damaged specimens which were later rehabilitated have shown an increase in load carrying capacity compared to the control specimen.
\end{abstract}

\section{Keywords:}

Enhancement; Externally bonding; Flexure strength; Glass fiber reinforced polymer; Retrofitting.

https://rengj.mosuljournals.com

Email: alrafidain_engjournal1@uomosul.edu.iq

\section{INTRODUCTION}

The use of fiber reinforced polymer (FRP) to strengthen reinforced concrete structures has grown and become a known technique. The lightweight and formability of these fibers have made them non-corrosive and resistant to chemicals, so they are the right choice for external reinforcement[1]. Many of the practical investigations conducted in the past have shown that the use of polymer fiber in the strengthening has several benefits compared to conventional methods, this is because of their high strength, low weight and improved durability [2].
There are three known types of polymer fiber used in the civil structures namely glass, aramid, and carbon fiber. The physical and chemical properties of these fibers vary not only from one type to another but also differ for the same fiber type [3]. Al-Luhybi[4] investigated the effect of wrapping standard cylinders $(150 \times 300 \mathrm{~mm})$ by GFRP sheets on its compressive strength, where it was observed from the results that wrapping using fiberglass sheets increased the capacity of cylinders. Meisam et al.[5] Conducted experimental study to investigate the effect of FRP strengthening on 
compressive strength of the concrete prisms. The researchers casted 17 concrete prisms, the variables in their study were the types of FRP used in wrapping, where carbon and glass reinforced polymer laminates were used. The effect of the specimens section on strength capacity of concrete was also investigated. Specimens were casted in square, rectangular, circular shapes with dimension of $(100 \times 100 \times 300 \mathrm{~mm}),(100 \times 150 \times 300 \mathrm{~mm})$ and(150 diameter $\times 300$ long) respectively. The results have shown that the increase in strength for specimens wrapped with CFRP was higher than the specimens wrapped with GFRP laminates. The results also have shown that cylindrical specimens were higher in compressive strength values compared to other specimens. In 2018, the

researchers Hassen et al.[6]studied the use of carbon fiber reinforced polymer (CFRP) (Near surface mounted (NSM) Technique with Roots Planted in strengthening shear resistance of prism beam. Four prismatic concrete beams $(75 \times 75 \times 500$ $\mathrm{mm}$ ) were casted and tested. The results have shown that this strengthening has increased the load capacity of beams. It was also observed that there was a decrease in mid span deflection. They also found that the use of this strengthening increased the flexural and shear resistance of the beams. Mohammad and Hana[7] investigated the effect of using glass fiber reinforced polymer sheets on the flexural and shear resistance of simple concrete beams. They tested four $(10 \times 10 \times 60 \mathrm{~cm})$ concrete beams. The results showed that when FRP sheets are used properly and proper bracing in concrete beams, there will be a marked increase in shear and flexural strength.

This study will investigate the effect of strengthening and rehabilitation using GFRP sheets on the flexural strength of concrete prisms.

\section{RESEARCH SIGNIFICANCE}

The purpose of the current research is:

1- To study the effect of strengthening of concrete prisms by using U-shaped Glass Fiber Reinforced Polymer (GFRP) sheets on the flexural strength of concrete prisms.

2- To Study the effect of increasing the number of GFRP layers on the flexural strength of prisms.

3- To Repair the failed concrete prisms with GFRP sheets.

\section{MATERIALS AND METHODS}

\subsection{Materials}

3.1.1Concrete: Concretewith compressive strength of $36 \mathrm{MPa}$ is specified for all the prisms. Ordinary Portland cement, locally available sand with fineness modulus (2.73) and locally gravel with maximum aggregate size of $(19 \mathrm{~mm})$ were used.

3.1.2GFRP Sheets and epoxy adhesive: The ultimate tensile stress $(f u)$ and Young's modulus $(\mathrm{E} f)$ of GFRP Sheet were determined by conducting tension tests on coupons cut from the sheet. The Young's modulus and the ultimate tensile stress of GFRP Sheet are calculated from load/strain curves and presented in Table 1. The properties of epoxy used for bonding the GFRP sheet are also presented in Table 1.

Table 1: Properties of GFRP Sheets and Epoxy.

\begin{tabular}{|c|c|c|c|c|}
\hline \multirow[b]{2}{*}{ Material } & \multicolumn{4}{|c|}{ Properties } \\
\hline & $\begin{array}{l}\text { Ultimate } \\
\text { Tensile } \\
\text { Stress } \\
\text { (MPa) }\end{array}$ & $\begin{array}{c}\text { Young’s } \\
\text { Modulus } \\
\text { (MPa) }\end{array}$ & \multicolumn{2}{|c|}{ Ultimate Strain } \\
\hline GFRP Sheet & 108 & $30 \times 10^{3}$ & \multicolumn{2}{|c|}{$2 \%$} \\
\hline & \multicolumn{4}{|c|}{ Properties } \\
\hline Material & $\begin{array}{c}\text { Tensile } \\
\text { Strength } \\
(\mathrm{MPa})\end{array}$ & $\begin{array}{c}\text { Flexural } \\
\text { Strength } \\
(\mathrm{MPa})\end{array}$ & $\begin{array}{c}\text { DensityK } \\
\mathrm{g} / \mathrm{m}^{3}\end{array}$ & $\begin{array}{c}\text { Compressive } \\
\text { Strength } \\
(\mathrm{MPa})\end{array}$ \\
\hline $\begin{array}{c}\text { Epoxy } \\
\text { Adhesive } \\
\text { (Epoxy } \\
\text { EP10) }\end{array}$ & 29 & 91 & 1060 & 83 \\
\hline
\end{tabular}

3.2. Test Specimens: Fourteen concrete prisms (760 mm-long) having cross-sectional dimensions of $(150 \times 125) \mathrm{mm}$ were cast using the same batch of the concrete. The effective span of all the prisms was kept as (711) $\mathrm{mm}$. Figure 1 illustrates the dimensions and testing procedure for prisms. Three concrete control prisms were designated as (B1-0, B2-0, B3-0), eleven prisms wrapped with different levels by changing the thickness of GFRP sheet. Three prisms wrapped with one layer of GFRP Sheet, three prisms wrapped with two layers of GFRP Sheet and three prisms wrapped with three layers of GFRP sheet, two prisms wrapped with four layers of GFRP Sheet. After testing the control prisms until failure, they were repaired and wrapped with one layer of GFRP Sheet to study their behaviour after strengthening. The details of the prisms are presented in Table 2. 


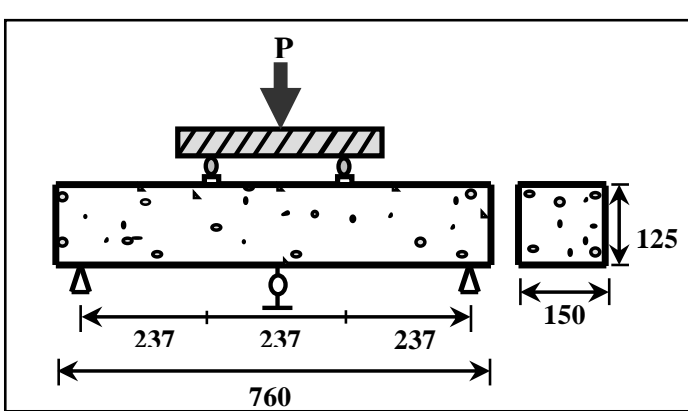

Fig. 1 The loading model of the prism (all dimensions in $\mathrm{mm}$ ).

Table 2:Details of the wrapping of prisms.

\begin{tabular}{|c|c|c|c|c|}
\hline \multirow{2}{*}{ Specimens } & \multicolumn{3}{|c|}{ " prism size } & \multirow{2}{*}{$\begin{array}{l}\text { No. of } \\
\text { GFRP } \\
\text { Sheet }\end{array}$} \\
\hline & $1(\mathrm{~mm})$ & $\mathrm{b}(\mathrm{mm})$ & $\mathrm{h}(\mathrm{mm})$ & \\
\hline B1-0 & \multirow{3}{*}{760} & \multirow{3}{*}{150} & \multirow{3}{*}{125} & \multirow{3}{*}{0} \\
\hline B2-0 & & & & \\
\hline B3-0 & & & & \\
\hline B4-1 & \multirow{3}{*}{760} & \multirow{3}{*}{150} & \multirow{3}{*}{125} & \multirow{3}{*}{1} \\
\hline B5-1 & & & & \\
\hline B6-1 & & & & \\
\hline B7-2 & \multirow{3}{*}{760} & \multirow{3}{*}{150} & \multirow{3}{*}{125} & \multirow{3}{*}{2} \\
\hline B8-2 & & & & \\
\hline B9-2 & & & & \\
\hline B10-3 & \multirow{3}{*}{760} & \multirow{3}{*}{150} & \multirow{3}{*}{125} & \multirow{3}{*}{3} \\
\hline B11-3 & & & & \\
\hline B12-3 & & & & \\
\hline B13-4 & \multirow{2}{*}{760} & \multirow{2}{*}{150} & \multirow{2}{*}{125} & \multirow{2}{*}{4} \\
\hline B14-4 & & & & \\
\hline
\end{tabular}

3.3.Specimen Preparation: After the prisms complete the treatment period (28) days, the external strengthening stage begins, but before wrapping the prisms and laying the bonding material, the surface of the prisms were prepared by carefully cleaning the surfaces of the specimens, and then starting the process of roughing the surface of the specimens with a serrated metal brush. After completing this process, the surface is cleaned of dust by an air blower, the prisms must be completely dry before wrapping. The bonding material was epoxy system which consists of two parts, resin material and the hardener material, these are prepared and mixed with a ratio of (1:3). The material are mixed thoroughly and for at least one minute at room temperature. A layer of epoxy is placed on the surface of the prisms using a paintbrush, and a layer of GFRP sheets saturated with the bonding material is also placed directly on the prism surface, the process of placing GFRP sheets on the surface of the prisms is accompanied by continuous pressure to ensure that there are no voids between the sheets and the concrete surface, and to remove excess epoxy. If the prismwas wrapped in more than one layer, an epoxy layer was placed on the outer surface of the first layer to allow adhesion of the second layer. In the final step of the wrapping process, the GFRP sheets were installed on the surface of the prisms by pressing themto remain interconnected by using mechanical clamp until the adhesive had cured. The specimens were left for seven days before being tested. All specimens were strengthened with GFRP and GFRP was present on the entirelength of the specimen.

3.4.Test Setup and Procedure:The prisms were tested in a four point loading setup as shown in Figure 1. The prisms have been loaded to failure, for each increment in the load, the vertical deflection was measured at midspan of the prism.

\section{RESULTS AND DISCUSSIONS}

\subsection{Strengthening Prisms}

4.1.1 The effect of GFRP sheets on flexural strength of prisms :Table 3 shows the failure loads of prisms which were strengthened by GFRP sheets with different thicknesses.

\begin{tabular}{|c|c|c|c|}
\hline Specimens & $\begin{array}{l}\text { No. of } \\
\text { GFRP } \\
\text { Sheet }\end{array}$ & $\begin{array}{c}\text { Failure } \\
\operatorname{Load}(\mathrm{kN})\end{array}$ & $\begin{array}{c}\text { Average } \\
\text { Failure } \\
\text { Load }(\mathrm{kN})\end{array}$ \\
\hline B1-0 & \multirow{3}{*}{0} & 16.1 & \multirow{3}{*}{15.3} \\
\hline B2-0 & & 16.2 & \\
\hline B3-0 & & 13.7 & \\
\hline B4-1 & \multirow{3}{*}{1} & 25.8 & \multirow{3}{*}{25.8} \\
\hline B5-1 & & 27 & \\
\hline B6-1 & & 24.5 & \\
\hline B7-2 & \multirow{3}{*}{2} & 44.1 & \multirow{3}{*}{45.5} \\
\hline B8-2 & & 44 & \\
\hline B9-2 & & 48.5 & \\
\hline B10-3 & \multirow{3}{*}{3} & 67.7 & \multirow{3}{*}{67.7} \\
\hline B11-3 & & 72.6 & \\
\hline B12-3 & & 62.7 & \\
\hline B13-4 & \multirow{2}{*}{4} & 58.8 & \multirow{2}{*}{55.4} \\
\hline B14-4 & & 52 & \\
\hline
\end{tabular}

Table 3: The result of ultimate loads of prisms

As shown in table 3 , it is noticed that the carrying capacity of prisms wrapped with one, two, three layer increased by external strengthening and this increase depends on the number of wrapping layers. Figure 2 shows the percentage increase in carrying capacity according to the increase in the number of wrapping layers. 


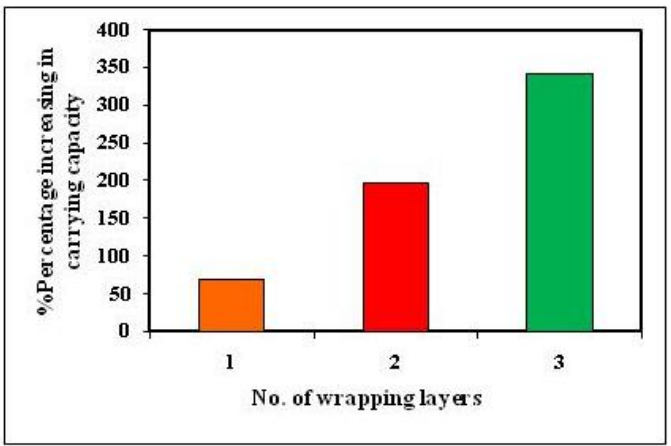

Fig. 2Percentage increasing in carrying capacity of strengthening prisms

It is also noticeable from table 2 that the carrying capacity of the prisms wrapped with four layers was low when compared to the prisms wrapped with three layers, and this contradicts to what was expected. The reason for the low carrying capacity of these prisms was the result of the early failure of these prisms due to the debonding of the wrapping layers. This type of failure has occurred in both prisms (B13-4 and B14-4). This failure occurs because of an occurrence of a diagonal shear crack in the constant shear region, known as critical diagonal crack debonding (CDC Debonding). The explanation for this is that the prisms flexural strengthened so that the end of the sheet has located in an area where the shear force is high (the end of the sheet next to the support), in this case a shear crack will occur at the end of the sheet. Increasing the width of the shear crack leading to an increase in the interfacial stresses between the sheet and the concrete which in turn leads to the final failure of the prism by debonding the sheet from the concrete [8]. Figure 3 shows the failure mode of the prism wrapping with four layers

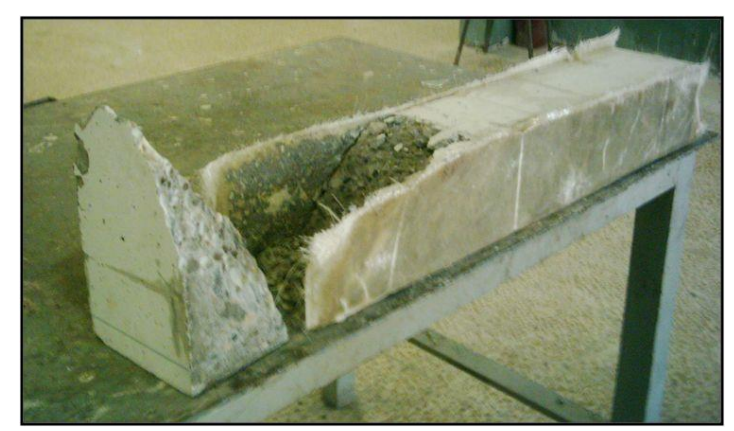

Fig. 3 The failure shape of prisms after debonding GFRP sheets

4.1.2 Relationship of (Load-deflection) for prisms externally wrapped with GFRP sheets:
Figure 4 shows the relationship of (load-deflection) for control prisms and for prisms wrapped with one, two, three layers. These values are the average of the three samples.

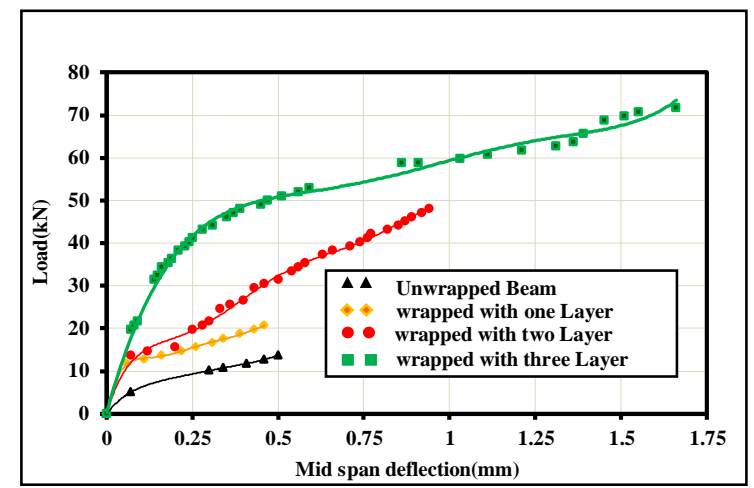

Fig. 4 Curves of (Load-Deflection) relationship of concrete prisms

One thing to note from the figure is that the curves are at first convergent and start with a linear relationship almost in the early stages of loading, it's noticed by increasing the load on the prisms, a gradual divergences in the curves where the GFRP sheets begin taking their role in controlling the cracks and the deflection. At a constant load value, it is found that the value of deflection of the wrapped prisms was less than the value of the deflection for control prisms (unwrapped prisms). This means that the external wrapping increases the absorption capacity of the wrapped prisms and the percentage depending on the number of wrapping layers. The toughness of the prisms load can be calculated through the curves of the (Loaddeflection). Where it is equal to the area under the entire (load-deflection) curve[9].The measurements of the deflection for all prisms were not for the end of the test or in other words, they were not until the prisms reached the failure, because the dial gauge was raised so that the damage was not exposed and therefore we could not calculate the toughness of each prism exactly. However, we can conclude from figure 4 that the external wrapping for prisms by GFRP sheets have shown higher values for deflection and loads at the ultimate stage than unwrapped prisms. This means that the area under the (load-deflection) curves of wrapped prisms will be greater than the area under the unwrapped prisms curves, and this gives a clear indication that the toughness of the wrapped prisms will be greater than the toughness of the unwrapped prisms.

4.1.3 The effect of GFRP sheets as external wrapping on the failure mode of the prisms:The failure of the unwrapped prisms was flexure failure, brittle and without any warnings. It began with the 
emergence of a crack from the bottom and middle of the prism and then spread vertically to the top. Figure 5 illustrates mode of failure for the unwrapped prisms.

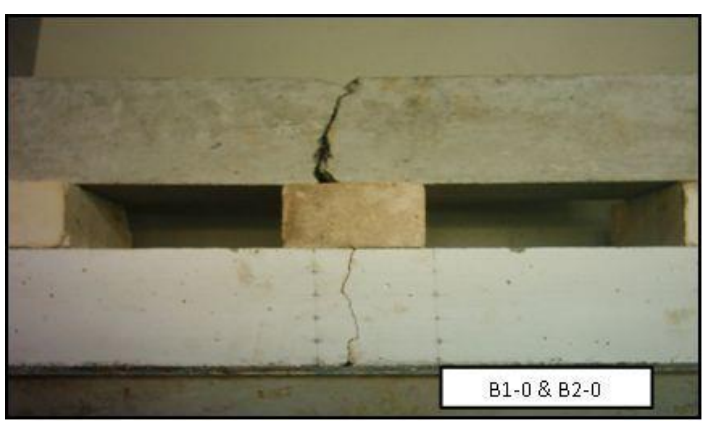

Fig. 5 Mode of failure for the unwrapped prisms

The failure of the prisms wrapped with GFRP sheets was different from the failure of the unwrapped prisms where wrapping has taken an important role in controlling the cracks in the prisms in terms of number and width, limiting their extension and delaying their appearance. Figure 6 shows the shape of the failure of the wrapped prisms it is noted that the cracks formed in the wrapped prism with a single layer are in large numbers and with very little width and length almost equal to the height of the prism is much like a network. These cracks appeared intensively in the last third of the loading, by the cracks formed in the prisms wrapped with two and three layers the shape of the cracks differed from the cracks in prisms wrapped with one layer in terms of few numbers and increase the width, in addition to the wide distances between one crack and another, the final failure of these prisms was also broken between the two loading points.Prior to reaching the final failure there are some points recorded such as hearing loud voices on GFRP sheets because of their separation from concrete due to the growing and widening of cracks in concrete, especially when carrying capacity reach $(70-80 \%)$ of the ultimate load.

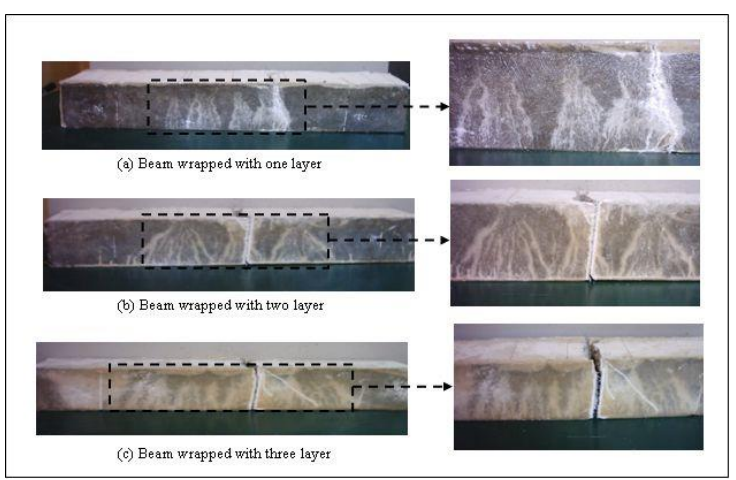

Fig. 6 Failure shapes of wrapped prisms

\subsection{Retrofitting prisms}

The failure of unwrapped prisms was broken between the loading points. In order to rehabilitate these prisms, the prism was initially treated at the failure zone. This treatment is done by sticking the separated parts of the prism by using bonding material,which is high viscosity epoxy type (Concresive 2200). After laboratory tests on this material, the compressive strength was found to be $62 \mathrm{MPa}$ and tensile strength equal to 18.8 MPa.Treatment steps can be summarized as follows:

- Cleaning the surface of the failure well using a metal brush and being careful not to lose pieces of concrete, especially coarse aggregate during cleaning.

- A layer of epoxy is placed on both surfaces, followed by a strong gluing of the two parts, with an additional layer around the contact area and the four sides around the failure surface to ensure that the surfaces are well bonded.Figure 7 shows the shape of the prism before and after treatment.

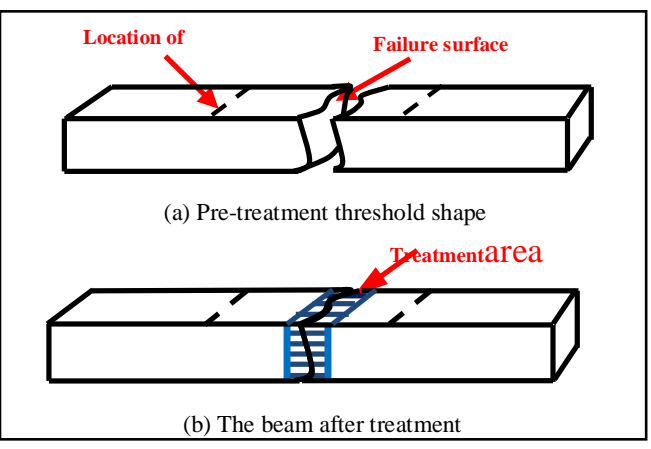

Fig. 7 The shape of the prism before and after treatment

- The concrete prisms are placed inside the molds in which they are cast, to ensure the stability and straightening of the prism during the treatment period. The prisms are left on this position for three days in order to epoxy take sufficient time to be fully stiffened.Figure 8 shows one of the prisms that was processed after extraction from the casting mold.

After three days, the two prisms (B-R-S1-1) and (B$\mathrm{R}-\mathrm{S} 2-1)$ were taken and wrapped with one layer of 
GFRP sheets, after finishing the wrapping process, the samples were left for a week before the test.The prisms were tested and for each increase in the load, the readings of dial gauge were taken.

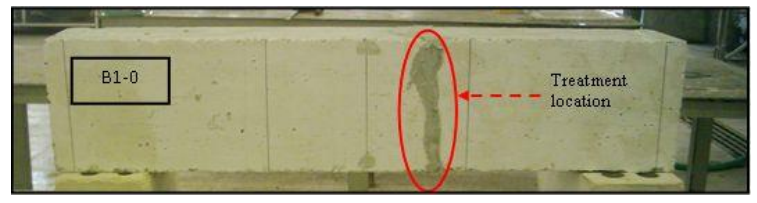

Fig. 8 The Treatment prism

It was observed from the results of the failure load that the damaged and retrofitted prisms with one layer of GFRP sheets (BR-S1-1) and (BR-S2-1) showed a clear change in their behavior.The average of the ultimate load was found to be 30.8 $\mathrm{kN}$, which is a higher load value than the prisms failed when they were unwrapped, where the failure load of the prism(B1-0) was equal $16.1 \mathrm{kN}$ and the failure load of the prism(B2-0) was equal to 16.2 $\mathrm{kN}$, this means that the increase in the ultimate load has reached to $90.7 \%$. This value is also higher than the failure load for the undamaged prisms that were strengthened by one layer of GFRP sheets which was equal to $25.8 \mathrm{kN}$, that is the percentage increase here reached the amount (19.4\%) and this means two things:

- Firstly, it means that theprismreturned to its previous status as one part.

- Secondly, itmeans the carrying capacity of damageprisms is increased and behave as a strengthened virgin specimen

Figure 9 shows the curves of the (load-deflection) relationship of the unwrapped concrete prism(control prism), strengthened prism with one layer and ofthe damaged prism that retrofitted by wrapping it with one layer of GFRP sheets, where it can be seen that the retrofitted prism is tougher than the prisms, and that its behavior is almost similar to the behavior of the prism wrapped with one layer.

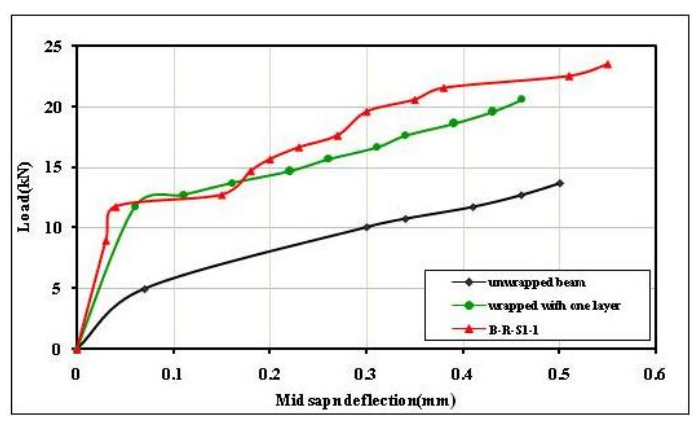

Fig. 9 (Load-Deflection) relationship of the unwrapped concrete prism, strengthened prism with one layer and the rehabilitated prism wrapped with one layer

The failure of the prisms (BR-S1-1) and (BR-S2-1) was broken in a new location that was not previously treated, this means the strength of the bonding between the two connected parts, in addition to the appearance of cracks in the prisms in the same manner as in previously tested prisms.Figure 10 shows the failure of one of the rehabilitated prisms.

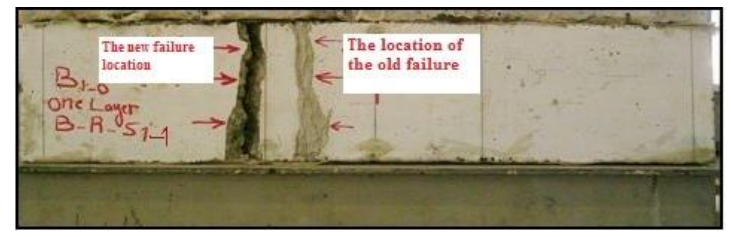

Fig.10 The rehabilitation of the prismafter failure

\section{CONCLUSION}

Based on the above,the following conclusions are presented:

1-The flexural strength of the prisms has increased by using external wrapping of GFRP sheets and with proportions depending on the number of layers of wrapping, where the increase in the flexural strength of the three-layer wrapped prisms reach to $(342.5 \%)$.

2- External wrapping by using GFRP sheets increases the toughness of the prisms.

3-At the same load, the wrapped prisms showed less deflection than the unwrapped prisms.

4-External wrapping played an important role in reducing the number, width and intensity of cracks in wrapped prisms.

5-prisms rehabilitated using GFRP sheets have shown similar behavior to unaffected prisms which has strengthened with by single GFRP sheets.

\section{REFERENCES}

[1] A. Khalifa, W. J. Gold, A. Nanni and M. I. Abdel Aziz, "Contribution of Externally Bonded FRP to Shear Capacity of R/C Flexural Members,"Journal of Composites for Construction, Vol. 2, Issue: 4, pp. $195-202,1998$.

[2] S. H. Hashemi, R. Rahgozar and A. A Maghsoudi, "Flexural testing of high strength reinforced concrete beams strengthened with CFRP sheets,"IJE Transactions B: Applications, Vol. 22, Issue: 2, pp. $131-146,2009$.

[3] A. M. Elarbi,"Durability performance of FRP strengthened concrete beams and columns exposed 
to hygrothermal environment," PhD Thesis, Wayne State University, Detroit, Michigan, 2011.

[4] A. S. Al-Luhybi, "Contribution of externally Bonded GFRP Sheets to Flexural and Shear Capacity of Concrete Members,"M.Sc. Thesis. University of Mosul, Mosul, Iraq, 2006.

[5] R. Meisam, M. S. Abdul Rahman, A. Yusof and K. Kiarash, "Behavior of different shape of concrete prism strengthened with FRP material under compressive axial,"Australian Journal of Basic and Applied Sciences, Vol. 7, Issue: 4, pp. 203 - 212, 2013.

[6] D. R. Hassen, A. Abdul Samad, N. Mohamad, A. A. Azeez, and A. N. Attiyah, "Using CFRP NSM technique with roots planted in concrete to strength of prism beam for shear,"International Journal of
Engineering and Technology, Vol. 10, Issue: 3, pp. $239-242,2018$.

[7] R. Mohammad and T. Hana, "An experimental study on shear and flexural strengthening of concrete beams using GFRP composites,"International Journal of Integrated Engineering, Vol. 3, Issue: 1, pp.1-7, 2018.

[8] J. G. Teng and J. F. Chen, "Debonding failures of RC beams strengthened with externally bonded FRP reinforcement: behaviour and modelling,"(APFIS 2007), Asia-Pacific Conference on FRP in Structures, 12-14December2007, Hong Kong, China, pp.33- 42, 2007.

[9] ACI Comittee 544., "State of The Art Report On Fiber Reinforced Concrete,"ACI 544.1R. American Concrete Institute, Vol. 96, pp. 42 -55, 2002.

\title{
تقوية وإعادة تأهيل العتبات الخرسانية باستخام صفائح الألياف الزجاجية
}

\author{
بيار جعفر السليفاني \\ dr.bayar.alsulayvani@uomosul.edu.iq

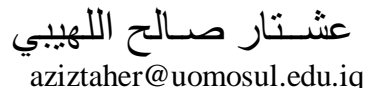 \\ aziztaher@uomosul.edu.iq
}

جامعة الموصل - كلية الهندسة ـ قسم الهندسة المدنية

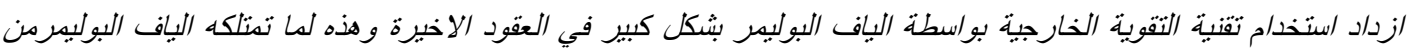

الملخص

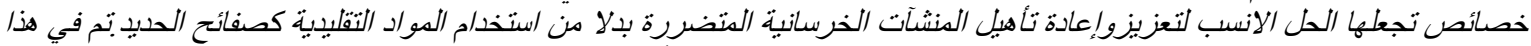

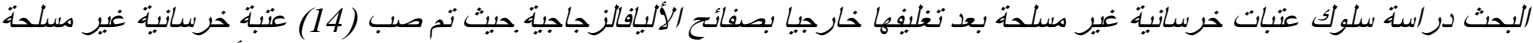

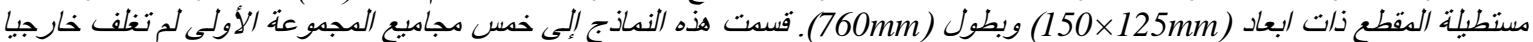

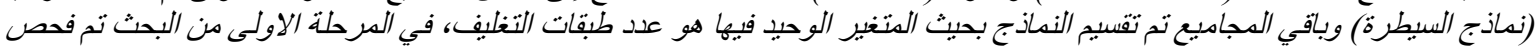

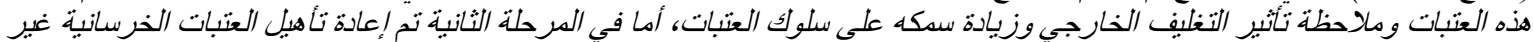

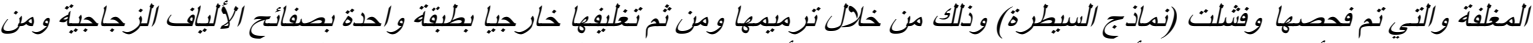

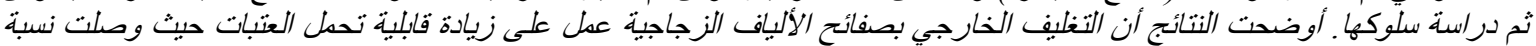

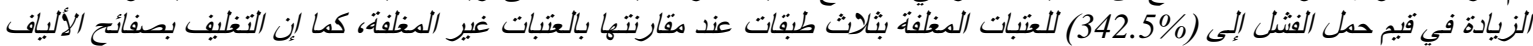

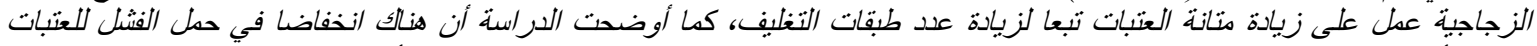

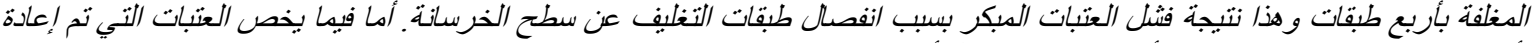

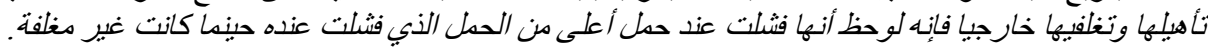

$$
\text { تعزيز، التغليف الخارجي، مقاومة الاثثناء، الباف البولبير الزجاجية، ترمبيم. }
$$

